\title{
Systems thinking benefits in supply change management: an illustration of the viable systems model in a Supply Chain
}

\section{Diana Chronéer*}

Division of Industrial Management, Luleå University of Technology, S-971 87 Luleå, Sweden

Fax: +46 920492339

E-mail: diana.chroneer@1tu.se

*Corresponding author

\section{Anita Mirijamdotter \\ Department of Informatics, Växjö University, SE-351 95 Växjö, Sweden \\ E-mail: anita.mirijamdotter@vxu.se}

\begin{abstract}
Existing product development models are solely an organisational matter. They do not take into consideration the whole Supply Chain (SC) and its different actors. In this article, we investigate how Supply Chain Management and Viable System Model (VSM) can support and create an effective use of information in product development and hence identify critical linkages in the SC. The aim is to introduce VSM as a framework that enables an analysis of companies' SCs and visualise vital inter-organisational relationships that should be integrated in product development.
\end{abstract}

Keywords: lead user; process industry; product development; SCM; Supply Chain Management; VSM; Viable System Model.

Reference to this paper should be made as follows: Chronéer, D. and Mirijamdotter, A. (2009) 'Systems thinking benefits in supply change management: an illustration of the viable systems model in a Supply Chain', Int. J. Intelligent Systems Technologies and Applications, Vol. 6, Nos. 3/4, pp.227-248.

Biographical notes: Diana Chronéer is a Researcher in Industrial Management at the Department of Business Administration and Management at the Luleå University of Technology in Sweden.

Anita Mirijamdotter is a Professor of Informatics at the School of Mathematics and Systems Engineering at the Växjö University, Sweden. 


\section{Introduction}

New Product Development (NPD) is a risky and uncertain enterprise and there is an extensive amount of research that emphasises the importance of integration and collaboration in order to decrease development time (e.g. Moenaert et al., 1994; Griffin and Hauser, 1996; Swink and Song, 2007). Research shows that building bridges between functions and to suppliers and customers increases the likelihood of success for the company. These bridges can take the form of cross-functional teams with R\&D/manufacturing/marketing integration (Song, Montoya-Weiss and Schmidt, 1997), strategic partnerships (Magrath and Hardy, 1994), which can be with both suppliers (Swink and Mabert, 2000) and customers (Campbell and Cooper, 1999). It is stated that collaboration can speed up the technological progress within the company, but it requires an increasing amount of resources to fully handle and control the product development process (Sobrero and Roberts, 2002). Companies often have well-known strategies that support intra-organisational relationships, for example: streamlining each stage of development; conducting parallel development activities; release of a package consisting of upgrades in product design, service support and business processes; and integrating information technology into the development process to increase communication (Towner, 1994). However, it is equally important to have strategies for interorganisational relationships that enable shorter product development time. Such strategies are designed to involve suppliers and customers in product development (Neale and Corindale, 1998), and to have strategic management of supplier-manufacturer relations (Sobrero and Roberts, 2002). Several researchers emphasise the importance of supplier collaboration in product development and that it is essential to integrate them in the product development process (Corswant and Tunälv, 2002; Petersen, Handfield and Ragatz, 2005).

Further, customers can be seen as sources of competence and they can step out of their traditional roles as consumers to become co-creators in product development (Prahalad and Ramaswamy, 2000). A way to come closer to customers and obtain information about future requirements is through various forms of user involvement including lead user, since the challenge for companies today is to find an accurate tool for discovering information about future needs and wants of the customer (von Hippel, 1986). In general, lead users adopt innovation before others and are more motivated to innovation, i.e. to realise their new ideas and unfulfilled needs. However, it is a risky business because customers, also as lead users, often have problems to articulate their future needs and requirements, especially in markets with short product life cycles and where emerging technologies revolutionise market needs (Barczak, 1994). User involvement in product development and innovation can also be seen as a coaching and teaching process, where the manufacturer guides its customers towards exploring their hidden needs and supplies them with products which fulfil these. Nevertheless, to improve customer relationships, feedback is of utmost importance, though difficult to obtain.

These findings concerning collaboration are mostly related to first-tier customer and first-tier supplier. We claim that to improve product development time there is a need to create links to second- and third-tier customers and suppliers, and that this is needed in product development work of today. In order to manage the product development process effectively, companies need to view their product development as part of a Supply Chain (SC) and interact and collaborate not only with the closest customer/supplier but also 
along the entire chain. Therefore, we ask: how can a company achieve an integrated view of their product development process in the SC that can shorten the development process further? A SC involves multiple processes, such as product development, production, logistics and information support that must be managed simultaneously. To illustrate the complexity of product development we turn to systems thinking, specifically the work of Checkland (1981), Beer $(1985,1989)$ Checkland and Scholes (1990) and Checkland and Poulter (2006) on managing organisations in complex environments within which these are embedded. In this article, we discuss the possibility of using an approach called Viable System Model (VSM), put forward by Beer, to achieve a holistic view of product development in the SC and hence create a more effective product development process. Thus, can the VSM be a framework that enables a 'holistic' view of product development in the SC?

In order to fulfil our purpose, we aim at investigating the information flow in the SC and the information that is needed by the different actors in their product development process. Given the difficulty of managing multiple information sources and types in product development work, this article attempts to address the following questions:

- What types of information are needed in development work for different actors in the supply/value chain?

- How can critical linkages be identified in the SC?

- How can information flow be managed that supports effective value creation in development?

- How can a holistic view of the interlinked development processes in the SC be obtained?

The article is organised as follows. To contribute to the field of SC and the understanding of the complex network linkages that are believed to underlie collaborative advantages in the SC, we briefly discuss in Section 2 how value is added in the SC and we also give a brief description of the model called VSM. Theoretically, this article demonstrates the possibility of linking the method of VSM to the Supply Chain Management (SCM) as a framework to analyse the complex network of linkages in the SC. In Section 3, we present the methods for gathering empirical data on product development in the process industry. The condensed data, complemented with web information, is then used in relation to, and discussions of, a simplified model of a SC. Based on these insights, we illustrate our argument in this article by applying the simplified model to VSM. Finally, conclusions of this exploration are given, including new issues for further investigation.

\section{Theoretical background}

\subsection{Value added Supply Chain}

As discussed above, one means to shorten development time is by interlinked intra-organisational and inter-organisational collaboration (Takeishi, 2001). A way to view collaboration as an interlinked process is by SC. In a SC, a company does not exist in isolation. It is dependent upon other companies, which supply the company with raw materials or which are the receiver of the company's product. A SC consists of a chain of 
companies whose purpose is to add value to a product. The first part of the SC often consists of transformation of material and development of material properties, and the second part consists of development of physical products and assembly of components, i.e. a product is transformed from the raw material to an end product, for instance a car. It is common in a SC that companies have their own Product Development Processes (PDP), which are not seen as part of other companies' PDP and collaboration takes place with those close to the operation in focus, i.e. first-tier customers and suppliers (see Figure 1). We argue that to achieve an effective and efficient product development process, there is a need to link up to the information flows of the SC.

Figure 1 The actors in the Supply Chain (see online version for colours)

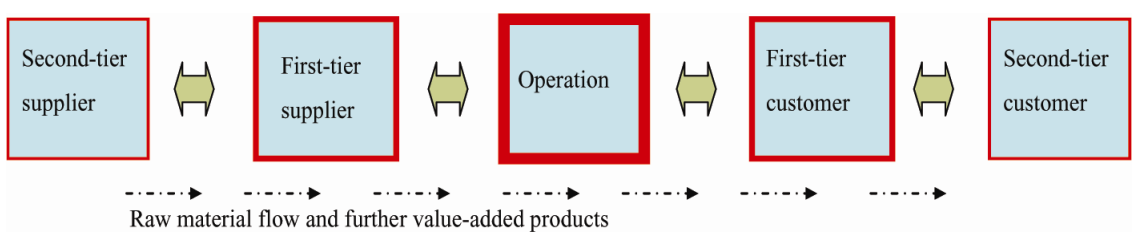

But, how do companies who are raw material suppliers (e.g. second-tier suppliers) obtain information and feedback further down the chain (e.g. second-tier customers)? The companies in the beginning of the SC often belong to the so-called process industry and develop and supply material that is further value-added along the SC.

There are some major characteristics that distinguish the process industry (e.g. mining and steel industries) from other manufacturing industries (e.g. automobile manufacturers). One characteristic is that the incoming material in the process industry often is raw material (e.g. ore), and it is transformed (developed) into a product (material) that can be further transformed by the customer and the customer's customers (i.e. second-tier customers), etc. However, a dilemma is that the transformation of a product (material) in customers' production processes may vary in different production processes, i.e. material properties can act differently due to parameters and tools used by various different customers.

Another characteristic that is different compared to other manufacturing industries is the complex production chain. The production chain may include a number of large and small production plants, sometimes operated and owned by different companies. There may be a long and complex chain structure of production units, and interfaces can create artificial obstacles, preventing sound product and process development and disconnecting the total chain of customer demands on the product (Lager, 2002).

Successful development of new products and new processes depends to a high degree on an understanding of this total chain structure (Tottie and Lager, 1995; see Figure 2) for illustration of the chain structure from ore to an automobile. Galbraith and Kazanjian (1986) described earlier on the value added process in the SC. The chain can be divided into two halves, i.e. upstream and downstream companies, and each stage has different success factors. There are some fundamental differences that illustrate the contrast between upstream and downstream companies. Galbraith thinks that downstream stages add value by producing a variety of products to meet varying customers' needs. The downstream value is added through advertising, product positioning, marketing channels and R\&D. 
Figure 2 A value-added Supply Chain in a manufacturing industry

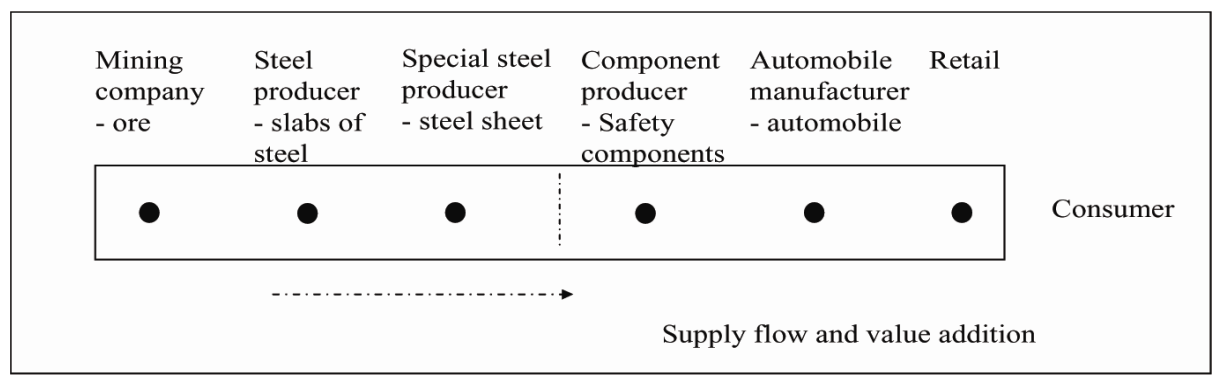

Source: Developed from Galbraith and Kazanjian (1986). The dashed line splitting the chain into two segments divides the industry into upstream and downstream.

Do companies belonging to the process industry need feedback from customers in the beginning of the SC? Research indicates that the developmental focus in a process industry is shifting from process to product (Strezo, 1999). This means that they need information and feedback on how their product is used and could be used further down the SC.

\subsection{Information flow in the Supply Chain}

In general, SCM has come to be defined in numerous ways and from different perspectives. Research on SCM is increasingly being based on a network view, both upstream and downstream - of developing collaborative advantages (Vachon and Klassen, 2006). SC is a very specific type of network that looks at the connections and dependencies between firms from raw material to final customer (Hertz, 2002) and facilitates an analysis of interlinked processes. We argue that, to reduce risks and uncertainties, companies should adopt a holistic view in their product development process that can take into account different and additional viewpoints, e.g. both a technical perspective such as manufacturability and a marketing viewpoint such as marketability (Ozer, 2004).

There has been extensive research on aspects like collaboration and cooperation with external actors in product development (Birou and Fawcett, 1994; Das, Narasimhan and Talluri, 2006), but very little attention has been given to product development in the entire SC, i.e. interlinked development processes where there is a need for effective exchange of information. Over the years, there have been substantial management changes that affect the need for information from a myriad of sources in product development work. But a product is not developed by itself; people and processes must come together in order for a product to be developed (Mintzberg and van der Heyden, 1999). Mintzberg and van der Heyden (1999) emphasise that it is important to demonstrate how a place is managed and organised, depicting critical interactions among people, products and information.

But how does information flow in the SC? As the name indicates, exchange of information is often described as a 'chain', but a SC consists of several different activities, processes and relationships, which can be illustrated not only as a chain, but also as a web or a hub (Mintzberg and van der Heyden, 1999; see Figure 3). 
Figure 3 Three ways to describe activities and relationships within a company; chain, web and hub (see online version for colours)
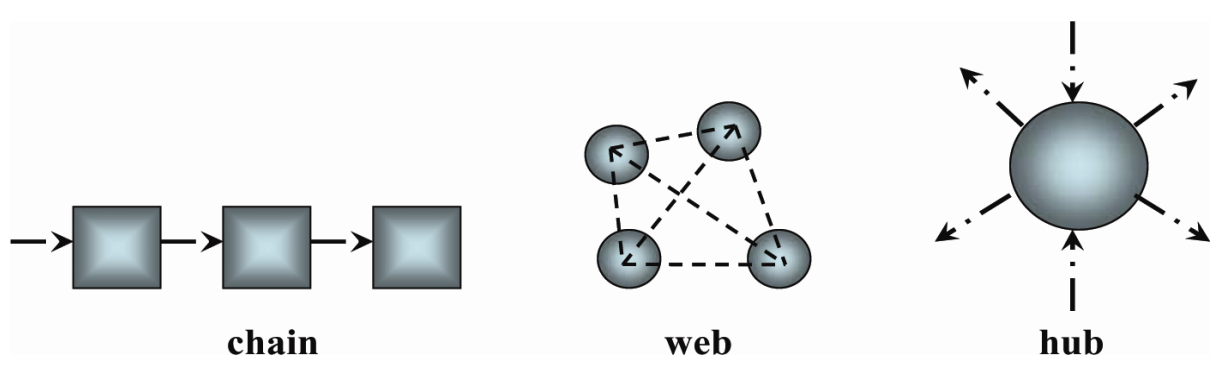

Source: Mintzberg and Van der Heyden (1999).

There are three main ways to describe activities and relationships within a company that conducts collaboration among internal functions, such as product development and manufacturing, as well as between the company and its external customers and suppliers. The traditional way to describe a flow of material and its transformation is through a 'chain'. Mintzberg and van der Heyden (1999) describe a chain as material entering a factory; it is then transformed into parts (production), which are then combined into final assemblies and then shipped to customers. On the contrary, webs allow a more open communication and continuous movement of people and ideas. Complex projects, like product development, may be viewed as a web where different actors, such as managers, engineers, salespeople and customers, must interact. Webs depict different 'nodes', e.g. people, teams and computers, connected in all kinds of ways. Finally, a hub illustrates a coordinating centre and depicts movements to and from one focal point.

Tatikonda and Stock (2003) summarise that a SC is a network of organisations involved, from beginning to end, in transforming and transporting materials and information to ultimately create and deliver a valued product to end customers. Firstly, information and materials flow up and down the SC. Secondly, each organisation creates and adds value to the entire product in the SC. Finally, the SC is a network of organisations where individual organisations must interrelate and interact to add value. SCM represents a way of managing business and relationships with other members of the $\mathrm{SC}$, and therefore, it also offers an opportunity to depict the synergy of both intra- and inter-company integration and management (Lambert, Cooper and Pagh, 1998).

Inter-company integration and coordination via information technology has become a key to improved SC performance (Barut, Faisst and Kanet, 2002). Today, new technologies enable customer-related information to be sent directly to suppliers, manufacturers and distributors, who can then use this information to respond instantaneously to change inventory levels. The idea of capturing and diffusing customer trends and preferences deep into SC member companies represented the beginning of a SCM revolution (Bechtel and Jayaram, 1997).

As shown above, the SC may not always be depicted as a 'chain' but rather as a complexity of multiple processes that needs to be managed, i.e. as a set of interdependent parts, which together make up a whole that is additionally interdependent of some larger environment (Anderson, 1999). These interdependencies can sometimes be better illustrated as a web or a hub depending upon the purpose of the relationship and on what type of activities are critical. The dependencies generate emergent demands, and in order to remain viable, these demands need to be met. Simultaneously, the interdependent parts 
need to be managed from a holistic point of view, i.e. they need to be managed and coordinated effectively in order to add value to the individual production processes and to individual product development. Therefore, we attempt to describe and analyse the information flow in a SC for the purpose of involving downstream companies in upstream companies development work and exploring the contribution of the VSM to analysing and identifying critical linkages in the SC.

\subsection{Viable System Model}

The VSM, developed by Stafford Beer almost three decades ago, is a generic systems framework that could be used to explain and analyse organisational viability, i.e. a capability to maintain an independent existence in the long term (Beer, 1989). In order for a system to continue to be viable in the face of environmental requirements, it has to have the capability of adaptation. It has to be able to change itself in response to environmental requirements. In his model, Beer (1979) defined five functions or subsystems that are essential for a system to be viable including how they interact to control an organisation. A key part of the VSM is the decomposition of a system into separate but interdependent subsystems with different roles (Shaw et al., 2004). These five subsystems of a viable system are as follows:

- $\quad$ subsystem 1 consists of operational processes - the 'plants'

- $\quad$ subsystem 2 oversees system 1's processes (and coordinates)

- $\quad$ subsystem 3 plans operational strategy inside the organisation, negotiates resources, monitors and controls

- subsystem 4 is concerned with developmental issues, outside the system and for the future

- subsystem 5 sets policy for the system to provide clarity about the overall direction, values and purpose of the organisation.

The subsystems are interrelated (see Figure 4). Subsystem 1 is indicated by a circle representing the operations and is itself built up of one or several viable system(s) in the same recursive structure. Subsystems 2-5 represent the management of system 1 and are embedded in a square at the top of the figure. Squares and triangles indicate regulatory functions. The lines between the symbols represent information flows. Each line (or channel) of the model illustrates two-way communication between the subunits and the environment. The system is connected to the environment by the development system, subsystem 4, and the operational system, subsystem 1, on each recursive level. The connection between the environment and system 4 aims at collecting information about long-term trends and activities, such as market place conditions, technology changes and external factors that are likely to be relevant in the future, and share the information with systems 3 and 4 on lower recursive levels. The connection between the environment and the operational units (system 1) represents information exchange of a more short-term nature, such as customer feedback. Note that each operational subsystem has its own specific environment, sometimes overlapping other operational systems. 
Figure 4 The Viable System Model

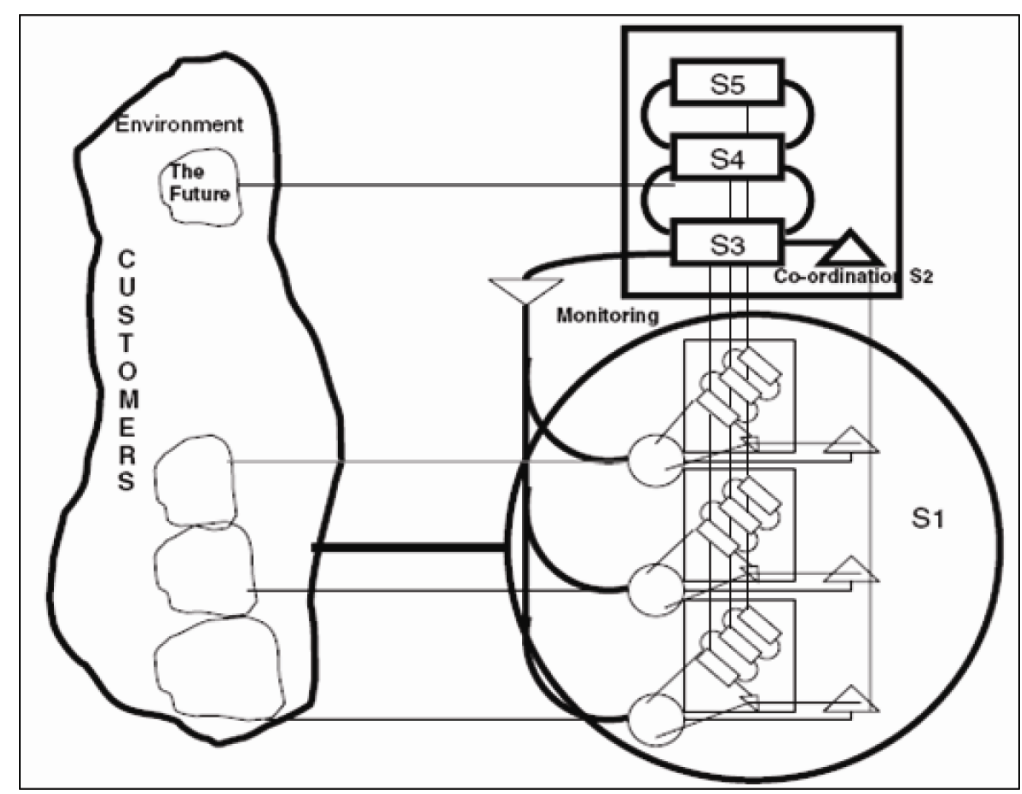

Source: Nyström (2006a,b) and Espejo and Gill (2007).

All of these subsystems must operate harmoniously with one another and with the environment via effective information and communication channels. Together, these subsystems can build a business network where the separate systems are interrelated via business processes and share dependencies such as resources, e.g. goods and information (Mumford, 2000).

The applicability of VSM is multi-fold. Some examples are given below. Brocklesby and Cummings (1996) find it more insightful to use the VSM as a design tool rather than as a diagnostic method, as highlighted by Beer (1985). They use VSM principles in redesigning the organisation as if from scratch. In addition, they find that the VSM enables the investigation of an organisation's vision and strategy, including its fit with operating procedures. Sutton (1995) argues that VSM should be viewed as an evaluation tool for assessing the manner in which viability is being maintained in an enterprise rather than mapping the presence of appropriate functions. VSM makes it possible to audit viability and to verify that the necessary systems are in place, and appraise the degree to which they are efficient, effective and empowering. Additional applicability is to determine how information could be used to better support operational and strategic decisions (Ormerod, 1995).

The VSM can also be used as a framework for delineating complex systems along lines of near decomposability (Shaw et al., 2004). Shaw et al. 'modularise' a complex business network and investigate the interaction between its 'modules'. This decomposability enables direct and indirect feedback loops, but their 'intensity of interaction' is greater for internal than for external connections. This justifies Shaw et al.'s (2004) conception of the modules as subsystems and of the overall network as having a heterogeneous structure rather than being a single homogenous object, i.e. VSM shows an open-system view where open systems are open because they exchange 
resources with the environment, and they are systems because they consist of interconnected components that work together (Anderson, 1999).

Because of its ability to support information exchange, communication, collaboration and empowerment, the VSM has also been used as a foundation for intranet design (Nyström, 2006a,b). To maintain and increase the viability of an organisation, VSM was used as a pattern when identifying and designing suitable functions supporting the critical information flows in organisations. In addition, functions among the subsystems of VSM were also identified and described. The model and its inherent functions provided an improved quality of the intranet. Further, the VSM sustaining empowerment and cooperation within organisations through its defined channels, enabled employees to collaborate more actively and participate in changes in the organisation.

Brocklesby and Cummings (1996) state that the VSM is not a simple model; it is highly practical, and it offers an insightful framework for thinking differently about organisations. Organisations have to match variety with variety. To remain viable, they have to satisfy the needs of individuals who have been targeted as customers or clients, and they have to continually innovate in order to stay one step ahead of the competition.

Some criticism has been raised against VSM. Jackson $(1988,1992)$ summarises and discusses the criticism in terms of 'principles' and 'purposes'. The model is described a machine or organism metaphor, that is, can the intricate monitoring and control systems be made operable in organisations? There is a problem with measuring how well a particular variable is actually performing. Another criticism concerns the concept of variety as an observer-independent objective measure. That is, different perceptions of reality continuously negotiated cannot simultaneously be observer-independent. Thirdly, the purposeful roles of actors in organisations are not taken into account. Fourthly, the model can be misused by powerful groups, i.e. it can serve authoritarian purposes. Finally, the VSM may also offer inappropriate principles to managers because the model neglects engineers' shared values and beliefs. In sum, some of these criticisms are also put forward in relation to other systems thinking methods and tools. The systems thinking tradition is based on engagement in real-world problems and claims that problems in the real world do not correspond to traditional disciplinary boundaries. Thus, systems concepts encourage an interdisciplinary practice. Also, systems concepts preserve a commitment to 'holism', i.e. to look at the world in terms of 'wholes' that exhibit some emergent properties rather than in a belief that insights can come from breaking wholes into their principal elements (Jackson, 1992).

In sum, we apply VSM in our SCM-model in order to achieve an understanding of how companies can obtain a more holistic view of their SC and how the information flow can be managed that supports effective value creation in product development.

\section{Method}

In this article, the results have emerged from two studies, in 2000 and in 2006, and are based on an inductive approach. The initial goal of the studies was to investigate the complexity of development work in the process industry. The first study is a survey among 50 companies in the process industry (companies belonging to the mining, steel, paper, chemical, food, plastic and rubber industries). The study had a qualitative approach in the perspective of development projects. Due to the explorative character of the questions, telephone interviews were considered suitable. A semi-structured interview 
technique was applied with a focus on certain issues, e.g. systematisation of information, and the content of needed information in product development.

The second study, conducted in 2006, consisted of a small survey with a follow-up discussion in a workshop with eight participants belonging to the process industry, more specifically the mining, steel and paper industries. The theme of the workshop was management of innovation and technology. The subject area of the survey concerned the need for customer collaboration and the use of lead user in development work.

In this article, we use these two studies in our illustration of the need for achieving a more holistic view in product development and for illustrating what type of information is needed in development work.

\subsection{Sample and analysis}

In both studies, the unit of analysis was product development. The criterion for selecting the companies in the first study was that they should be part of the process industry, i.e. produce a product that can be further value-added in the next stage of the value-chain (e.g. by customers in their production process). A sample of companies was taken from branch organisations. Companies were initially contacted by telephone for the purpose of ensuring that they were involved in development projects, identifying key respondents and soliciting cooperation. Out of 55 companies, 50 agreed to participate in the research. Table 1 shows the distribution of the companies with three categories: small, medium and large. The categorisation is based on the number of employees.

Table 1 Number of companies in sample by type of industry and size

\begin{tabular}{|c|c|c|c|c|}
\hline \multirow[t]{2}{*}{ Type of industry } & \multicolumn{4}{|c|}{ Size of the company } \\
\hline & $\begin{array}{l}\text { Small (no. } \\
\text { employees } \\
\quad<100)\end{array}$ & $\begin{array}{c}\text { Medium }(100 \leq \text { no. } \\
\text { employees } \\
<500)\end{array}$ & $\begin{array}{l}\text { Large (no. } \\
\text { employees } \\
\geq 500)\end{array}$ & Total \\
\hline Mining & 0 & 0 & 2 & 2 \\
\hline Steel & 0 & 1 & 8 & 9 \\
\hline Paper & 0 & 0 & 7 & 7 \\
\hline Chemicals & 6 & 6 & 3 & 15 \\
\hline Rubber & 1 & 2 & 3 & 6 \\
\hline Plastics & 2 & 2 & 0 & 4 \\
\hline Food/dairy & 0 & 1 & 6 & 7 \\
\hline Total & 9 & 12 & 29 & 50 \\
\hline
\end{tabular}

Note: Number of employees is the determinant of the size of the company.

Altogether, 50 companies participated with one respondent from each company. Data was gathered from structured telephone interviews with open-ended questions, enabling a rich understanding of the companies' current development work, which could be used additionally to explain the use of information in current and future development work. The majority of interviews were recorded, transcribed and sent back to the respondents for feedback, alterations, etc. All interview materials were then coded with a software technique called 'Non-numerical Unstructured Data Indexing Searching and Theorising' (N5), a computer package designed to aid users in handling non-numerical and unstructured data in qualitative analysis. The texts were first coded with nodes and organised into a 'tree' structure, enabling thorough qualitative analyses of the material 
concerning, e.g. the need for information in development work. We used this tree structure as a means to sort and arrange information that was related to value creation and use of information in product development. Then, we sorted out data that could illustrate a complexity in development work; value creation, information need/spreading, needs and changes in development work. The data analysis of these categories consisted firstly of multiple readings of the selected data and identifying the complexity of development work in the SC. Secondly, we made an interpretation of the complex context in development work in the process industry. Thirdly, we identified specific segments of information that are needed in the development process and the sources such as the need for external cooperation. Finally, we created a model that shows the complexity of the need for linkages development work to various sources in the SC.

The second study, in 2006, comprised four companies that represented the mining, steel and paper industries. Data was gathered through a survey with the focus on innovation, e.g. type, sources, driving factors and customer integration. The theme of the survey was then discussed with the participants in a workshop. Eight respondents, all belonging to $\mathrm{R} \& \mathrm{D}$ departments in the process industry answered the survey and participated in the workshop. This study added information of the need of using End Users in development work and therefore, the need to build linkages to them.

Further, we also use secondary data such as company reports and companies' internet homepages as illustrations of how products are further value-added in the SC. This data is not connected to the surveys.

\section{Result and discussion}

As stated previously, companies experience pressure to shorten their PDP, to utilise a wide range of information from different sources, and to collaborate with both suppliers and customers in their development projects. In this article, we propose that companies need to obtain and develop a holistic view of the product flow and transformation in the entire SC in order to shorten the development processes further. But, how can this holistic view be obtained by those who work with development? Can this be achieved by integrating the VSM perspective in the product development process? How can VSM enable a holistic view of product development in the SC?

Companies in the beginning of the SC (i.e. 'upstreamers') need to know how the material will be used further down the chain, e.g. the requirement of the steel weight, hardness, etc. - see the following quotes, taken from the two studies:

- An important component in development work is technical market support, which comes from input about trends and customers' demands. In development, teams work very closely with equipment suppliers. Networking with suppliers, which is more formal, has increased. It is important to have the 'customer presence', possibly through the sales team with qualified technicians, i.e. part of the marketing organisation.

- It is important that end-users are involved in development.

- Development must cover a larger part of today's value chain and realise what gives customers value. 
- Development should be more observant and sensitive so as to grasp the market signals.

- Today, development needs information concerning the customers or further down the chain (end-users).

- It is difficult to 'skip' our own customers in order to collaborate with our customer's customer.

Study two also indicates that external actors are important sources for successful development projects, and that, especially in product development, the customer is usually the driving force. However, the lead user perspective in the process industry is not solely in product development. Lead user can be involved in process development, whereas people with a good knowledge about the process as a whole are involved. Although the literature indicates that there are problems in the process industry with identifying lead users, all companies who joined the study recognised them. However, one company indicated that they did not know them well enough.

Survey two also indicates that it is more common to develop whole concepts, i.e. a specific customer need will be produced for a specific process at the customer. One company stated that if you do not understand customers and only have traditional products in you programme, only the price is left as a competitive weapon, which in the end will lead to smaller margins. One company in survey two saw advantages of lead user involvement in the ability to create close relationships with partner customers. But, there are several different reasons why companies in the process industry have problems to work with lead users in their development: customers are few and the products have long life cycles, customers have heterogeneous product needs. The respondents indicated, though, that lead user can serve as a contributor of novel product ideas. More often, though, companies in the process industry use lead users to understand the processes of their customers, thereby making the production more effective. But, how can developers obtain information further down the SC and manage it?

Traditionally, companies in the process industry, when involved in product development, have usually seen their nearby customers as their lead users. This is about to change and companies are trying increasingly to involve end users, i.e. 'second-tier' customers, of their products in their PDP. However, this is not easily achieved, because first-tier customers do not always want their suppliers to collaborate with 'their customers', their first-tier customers, i.e. the true end user of the product.

All the participants in the workshop agreed that the knowledge lead users have may be valuable for the development work. The knowledge coming from users can deal with end applications that do not yet exist on the market, and the developers can achieve a better knowledge about the future needs and wants of the customers.

In order to achieve effective product development and shorten the development process, it is not sufficient to obtain correct information; it is also essential to send the correct information. So specifically, what type of information flowing in the SC can support the inter-organisational PDP? Below there is an illustration of the aspects that are developed by the different actors in the SC and that finally end up in a product, e.g. a car. We illustrate the flow of value addition by different actors in a SC where the end product is a car and the raw material is iron ore (see Figure 5).

The management of product development is becoming increasingly complex, and information concerning the use and possible needs from those who use the product is 
increasingly important. Figure 5 illustrates a chain of actors in a SC starting with a raw material supplier (e.g. a mining company extracting iron ore and developing pellets) and ending with a car manufacturer that has to consider buyers of cars with various preferences for colour and interior design.

Figure 5 The Supply Chain and companies' individual Product Development Processes (see online version for colours)

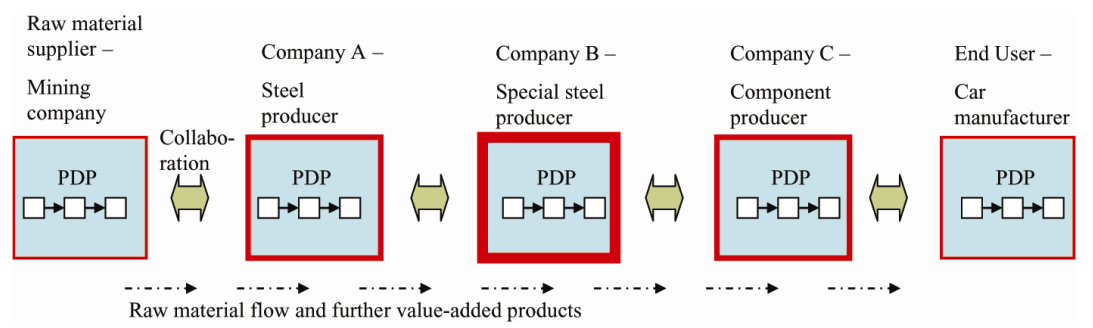

\subsection{The beginning of the Supply Chain}

In the beginning of the $\mathrm{SC}$, the raw material supplier provides the needed raw material that will be further value added. As an example, we take a raw material supplier that supplies upgraded iron ore products to the steel industry, custom-adapted mineral products to other industrial sectors, and products and technologies for mining. Pellets are sintered into centimetre-sized spheres of ore with a high iron content and uniform quality. Blast furnace pellets are used in the coke-based blast furnace process, which is the most common method of producing hot metal (molten iron for steel making). Some types of pellets are used in the direct reduction process to produce sponge iron, which in an alternative process route and also an initial stage in the chain of production from iron to steel. Products are developed in close collaboration with customers, through technical service in customers' production processes. This implies an intensive investment in the development of new pellet types for different steel making processes. ${ }^{1}$

The second step of the SC is illustrated with a company from the steel industry. Both material properties and production techniques are of interest in the steel industry. Material properties may for example be properties in the steel ingot that decrease the diffusion in the steel. Steel (e.g. sheet) is a product that can be produced in a variety of grades and strengths that decreases weight, lowers the material costs and simplifies production for customers. Commercial steel has undergone radical changes and developments over the past 10 years. Traditional types of steel have been refined regarding both dimensional tolerances and uniformity of mechanical properties, while numerous steel grades have been developed for new applications, e.g. cold-forming steels and quenched-and-tempered structural and abrasion resistant steels. The most important demands come from today's consumers. When buying products containing steel, they may have specific demands regarding, e.g. cost, life expectancy, appearance, strength, weight or environment-friendly properties. Lighter products are one category of product development, since high-strength steels are stronger than ordinary steels, allowing the customer to decrease the need for steel for a given task. Other aspects of developing high-strength steel are the extended useful life and improved durability of a product, and the reduced material cost. As an example, products will be stronger and more shock 
resistant. However, a problem is that these needs can be indirectly expressed as effective use of energy through reduced weight, cost-saving in transport, etc.

Our example in Figure 5, iron ore pellets are transported to Company A where they are transformed into ore-based steel slabs. Company A develops special steel grades for the customers, i.e. high-strength steel with the required width and properties. The steel grade has the right carbon content and exactly the right mix of alloys. The metallurgy is based on ore (from the raw material supplier), and the ore supplied consists entirely of pellets. In the steelworks, the iron is refined into steel in a converter (steel furnace) and oxygen is blown into the melt, which reduces the carbon content. Alloying elements are then added to the melt in order to achieve the right quality and the required type of plate material. In order to improve its properties further, the steel is often treated in an injection plant or by vacuum degassing in a ladle furnace. All the steel is then continuously cast into slabs in two continuous casting machines. A rolling mill produces heavy plate from slabs of various sizes and grades. After rolling, the plates are cut to the required lengths. To achieve high strength and wear resistance, combined with improved weldability and workability properties, the plates are heat treated and/or hardened after welding. ${ }^{2}$

\subsection{The end of the Supply Chain}

In the third step of the SC, the steel slabs are supplied to Company B, where the steel is produced in an integrated process extending from iron raw material to finished plate. Company B develops and supplies advanced high-strength steel that in the end reduces the weight of the automobile and increases the safety. Company B promotes this highstrength steel as an easier material to operate for designers, buyers, production managers and operators, and it has several qualities, such as:

- The high strength steels are stronger than ordinary steels, which lead to a reduced need for steel for a given task (lighter products) and a lesser need for resources both in production and in transport.

- Lesser need for steel reduces the material costs.

- High strength steels improve the reliability of production, since the material properties are more consistent (easier production).

Further, Company B can sell knowledge because new steels demand new knowledge and the company can sell expertise on how high strength steels should be used to improve competitiveness and profitability. ${ }^{2}$

In general, steel is one of the basic ingredients in the development of industry. Steel has to have different properties for different applications. Cars need strip steel with good formability and an attractive surface finish. Auto components, such as side impact beams, require high-strength steels that enable the manufacture of strong, thin and light constructions. ${ }^{3}$ Further, a car consists of specialised components such as doors, bumpers and a body manufactured from special steel. So, in order to fulfil the needs and requirements of the end user, Company $\mathrm{C}$ develops, manufactures and markets safety components for the automobile industry, where the main activity can be based on the technology of hardening boron steel in connection with compression stamping. This specialised technology allows the end user to use narrower tolerances, improved dimensional stability and reduced weight. Therefore, the technology can provide lighter, more cost-effective solutions in the product (the car). ${ }^{4}$ 
Finally, the components end up at the automobile manufacturer, where components are assembled into a complete car, which is then sold to a car dealer and finally ends up at the end user (the buyer of the car). This means that the car buyer, as the end user of the steel, is involved in various development processes, both company internal and external, including suppliers and first-tier customers. A typical passenger car contains more than 30,000 parts (Takeishi, 2001) and consists of various high-tech components that require complex development processes, e.g. fuel-cell technology (Lundbäck, 2004). The increase of complexity in products and business processes results in a need for new methodologies and innovative concepts to handle this complexity efficiently (Röder and Tibken, 2006). In future, it will be even more important to be able to select and collaborate with suppliers. However, in order to select suppliers, it is essential to analyse the SC and its actors, i.e. to make plain who are involved and which contribution each of them makes in the process of bringing added value to the product.

Because most firms are part of a complex supply network today, researchers (e.g. Taylor, 2005) state that it is of importance to understand the processes that make up the SC system. Taylor (2005) found that it is common that firms do not have a clearly defined picture of their SC structure and that value chain analysis highlights significant opportunities to improve SC performance and relationships. Another method for modelling inter-company SCs is based on interrelated product and process documentation (Röder and Tibken, 2006). However, this methodology focuses on modelling relationships between first-tier customers and suppliers but lacks in performing essential analysis of critical linkage in the SC. Today, companies' PDP are interlinked in an 'invisible' chain. Upstream companies need more often information about the product developed further down the SC. In a SC, two different flows of information can be visualised that flow in opposite direction:

1 Information from customers about customer needs and requirements (e.g. problems with current products or identifying how a current product/service is not meeting current needs).

2 Information from suppliers about, e.g. NPD possibilities.

Furthermore, competition today is no longer one company against other companies, but one enterprise network or SC against other networks and SCs (Röder and Tibken, 2006). Therefore, to understand this chain of PDP, we must define the SC with its actors and how they interact.

In conclusion, PDP are generally viewed as an internal concern for the separate company, where collaboration can occur with the nearby actor. In order to describe how the information flow in the SC that supports an effective value creation in development can be managed, it is essential to understand the context of each actor in the SC.

\section{Application of VSM}

As shown in the previous section, transformation from iron ore to steel to impact beams in cars is a complex process that requires tight collaboration and information exchange. Also, the possibilities of product development further down the chain depend to some degree on the properties that are developed in the beginning. Further, process and product developments are highly interrelated in a company in the beginning of the SC, e.g. 
a mining company extracting iron ore and developing pellets; a change in a production parameter can greatly impact the properties of the product's material. Today, as indicated by the quotes above, a main driver in development work in the process industry is not only the customer but also the end-user of the product. For process-based companies, this means that developers need to be familiar with the use of the product at the end of the $\mathrm{SC}$; the product's material properties must be transformable further down the SC. And, vice versa, downstream companies need to understand the properties of the material further up the chain so that they can influence the development of material properties.

In this article, We propose that companies need to obtain a holistic view in their product development and view their own product development process as a subsystem in a larger system. Since, the key part of the VSM model is the decomposition of a system into separate but interdependent subsystems with different roles, we suggest that it might be a valuable analytical tool for companies in finding the critical linkages and information sources, so that effective information and communication channels can be created. As Brocklesby and Cummings (1996) state, the VSM model offers an insightful framework for thinking differently about organisations.

It is useful to start the analysis of product development interlinked to other companies' PDP in the SC, so that they can support one another and hence be more effective. Large, complex SCs (systems) are too challenging to be addressed as a whole. For this reason, they first need to be broken down into sub-activities so that critical linkages and relationships can be visualised and sustained. Further, companies do not have an endless pool of resources; this analysis can help to allocate the right resource to the right place.

How can VSM be applied as an analytic tool? In Figure 6, we illustrate the above SC of Figure 5 seen through the lenses of VSM. In this model, the raw material supplier and various companies illustrate the system 1:s of VSM, while the end user segments represent different environments with which the SC interacts. So, the next thing to do is to reflect on the different kinds of analyses of the various subsystems, what kind of information these both produce and require, and what channels are available for disseminating the information. Below, we give some suggestions towards these kinds of analyses.

Firstly, subsystem 1 may consist of an analysis of the individual product development process, its stages from concept to introduction, the needed information in different stages and where this can be found.

Secondly, subsystem 2 consists of the coordination processes of the intraorganisational relationships. Here, it is important to allocate a resource that is to be responsible for the coordination processes within the company. This implies exchange of information and understanding the nature of the information that needs to be collected and exchanged for efficient coordination.

Thirdly, subsystem 3: internal strategies for how to manage the product development process and how to collaborate. Strategies for how to collaborate internally and with whom. 
Figure 6 Achieving a holistic view in product development in the Supply Chain (C1 and C2 illustrating that e.g. Company B has several customers to interact with) (see online version for colours)

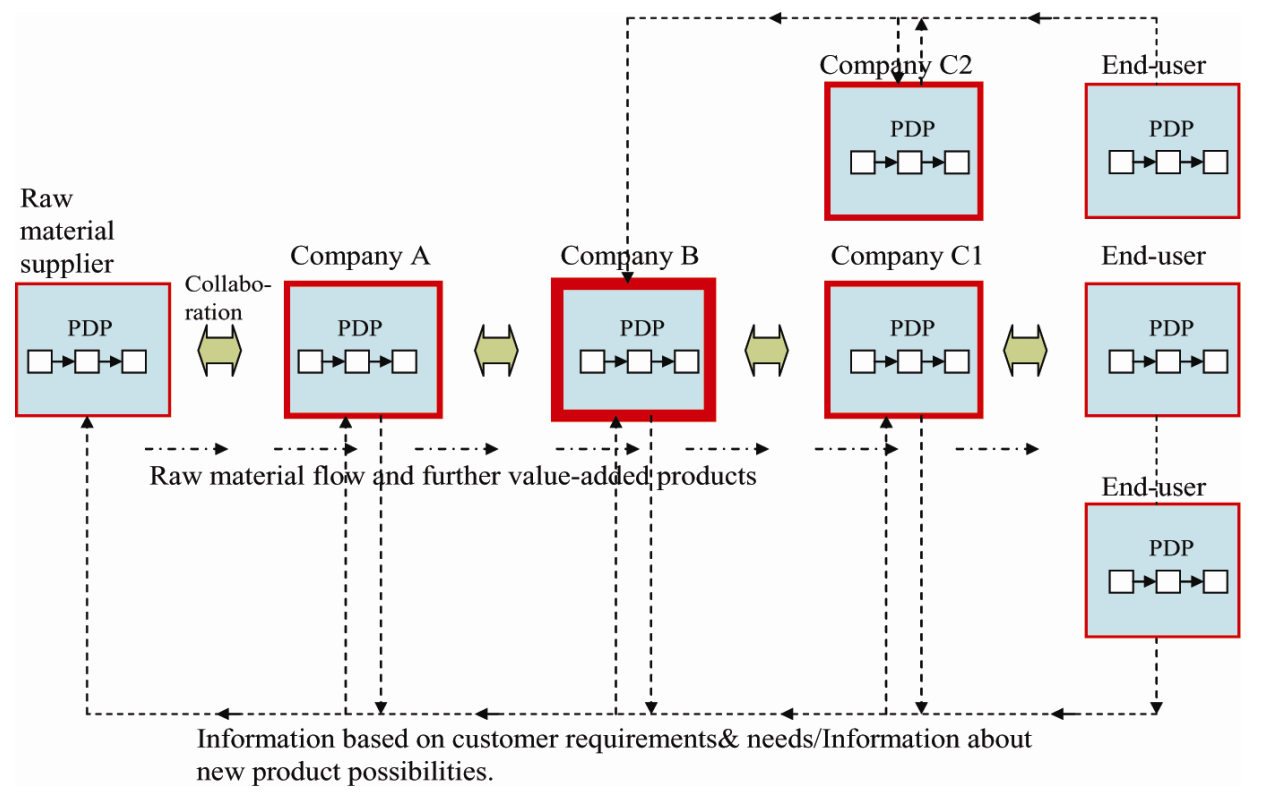

Fourth, subsystem 4: here is the analysis of the outside perspective and possibilities; which customers and suppliers should be part of the company's product development process. Such an analysis, following our argument in this article, points to an understanding of a product's place in the SC and to how value is added along the chain, and not only the first-tier customers and suppliers, but also for the second- and third-tier ones. What can second- and third-tier suppliers contribute in future products to secondand third-tier customers' products? What information do we need from second-and thirdtier customers/suppliers?

Fifth, subsystem 5: the policy function involves the final check against direction, values and purpose. One of the key conditions relates to how subsystems 3 and 4 are organised and interrelated. These two subsystems offer complementary perspectives on the whole system's main activity in that the first engages in the organisation's immediate business while the second looks for possibilities for the future. So, an important analysis is how the relation works between these subsystems and to what degree both are involved in policy setting, not giving too much weight to one or the other.

In our illustration above of the analyses involving particularly systems $1-3$, we focused on individual companies. However, an equally important analysis concerns how holistic managerial and coordinating processes can be enabled through information flows and functions for the whole SC.

The model, based on systems thinking, implies that the different system 1:s need to be managed both individually and taken together, and coordinated for the purpose of mutual adjustment between supporting functions and autonomous units, thus enabling synergistic operations and a coherent performance. In the SC perspective, we do not find any management and coordination system on this holistic level. Further, the different environmental segments are not clearly defined, nor their specific needs and requests. 
In sum, we apply VSM in our SCM model in order to achieve an understanding of how companies can obtain a more holistic view of their SC and how to manage the information flow that supports effective value creation in development work. However, we are aware that companies may be part of several, and sometimes overlapping, SCs. A firm has a much wider network of relationships than just one SC; a firm has often more than one product and sells to more than one customer. Therefore, firms will be part of more than one SC, sometimes complementary, sometimes competing. Since, increased integration is vital in developing competitive advantage among the firms in the SC, it seems necessary to reflect upon how the activities and resources are divided among SCs (Hertz, 2006). Also in this situation, we see the value of applying the VSM structure to Checkland's notion of a purposeful activity system (Mirijamdotter, 1998). In such modelling, VSM principles of management, communication, control and coordination are at the forefront and embedded into the philosophy of Checkland's Soft Systems Methodology, where the purpose is to illuminate different perspectives, debate and learn from these to reach agreement. Thus, by such an approach we get the potential for building up a coherent view of an integrating strategy for the various SCs of which the company might be a part.

\section{Conclusions}

In this article, we propose that companies in the process industry need to obtain a holistic view of product development from the perspective of the SC and to regard their own product development process as a subsystem in a larger system. We further argue that to decrease development time there is a need to create links to second- and third-tier customers and suppliers, i.e. when viewing product development as part of a SC, to interact and collaborate not only with the closest customer/supplier, but also along the entire chain. Therefore, we ask: how can a company achieve an integrated view of their product development process in the SC that can shorten the development process further?

One solution to the problem of achieving an effective and efficient product development process is to connect the information flows of the SC. Therefore, we discuss the possibility to use an approach called VSM to achieve a holistic view that includes support for information exchange, communication, collaboration and autonomy. The model is built up as set of five interacting subsystems, each with a specific function. These subsystems are essential for a system to be viable; through information and communication flows they ensure an organisation's capability of adaptation, i.e. ability to change itself in response to environmental requirements.

With such questions in mind as: what types of information are needed for different actors' value-adding development work in the SC?; How can critical linkages be identified in the SC?; How can information flows be managed that support an effective value creation in development?, we have examined some theoretical assumptions on information flows in a SC and also included two empirical studies.

In relation to interaction models, we find the web metaphor most appropriate to illustrate information flows in the SC. Webs illustrate open communication and a continuous movement of people and ideas. We find that complex projects, like product development, may be viewed as a web where different actors, such as managers, engineers, salespeople and customers, interact. Webs depict nodes in multiple connections. 
We also find that the most common external relationships in a SC are with closest customers and suppliers, so called first-tier actors. However, the two studies, briefly discussed in this article, indicate that both first-tier and second-tier customers and suppliers have a need of information that covers a large span of the SC. All parts of the $\mathrm{SC}$ are interested in knowing about customer needs and requirements, including problems with current products or how current products/services are not meeting current needs, and with obtaining information from suppliers about, e.g. NPDs and what possibilities these enable.

In the case of customer-initiated feedback, lead user is one approach. However, although all companies included in the two studies recognise lead users, they claim that there are problems with identifying them or that they do not know them well enough. The advantages they found of lead user involvement lie in the potential of creating close relationships with partner customers and contributors of novel product ideas. In addition, lead users are beneficial in assisting companies to understand the processes of the customer, hence making the production more effective.

A problem that remains is related to obtaining information from second- and third-tier customers. First-tier customers seldom want their suppliers to collaborate with 'their customers', i.e. their first-tier customers. Therefore, we illustrate processes and information flows in the VSM to address such problems and attend to advantages of a holistic view in SC product development, including the beneficiaries of information exchange throughout the chain.

The model, building on systems thinking, illustrates that, for the purpose of enabling synergistic operations and a coherent performance, in addition to manage individual companies, there is a need to manage and coordinate the whole SC. Further, the various environmental segments should be defined, together with specific needs and requests. Since, the key part of the VSM is the decomposition of a system into separate but interdependent subsystems with different roles and functions, including information flows and channels, we find that it can be used as an analytical tool for companies in finding the critical linkages and information sources, so that effective information and communication channels can be created. We agree that the VSM indeed offers an insightful framework for thinking differently about organisations.

Finally, since increased integration is vital in developing competitive advantage among the companies in the $\mathrm{SC}$, we notice the need to reflect upon how activities and resources are divided among several SCs in one and the same company. In this situation, we also see the value of applying the VSM for the purpose of illustrating different (and often competing) activities, in order to learn and to reach agreement on a common strategy.

An additional potential of VSM is related to the use of Information and Communication Technologies (ICT) and how these enable customer-related information to be sent directly to suppliers, manufacturers, and distributors. To use this mass of information, its channels, receivers, packaging, etc. these need to be designed wisely to allow effective responses. ICT is depicted as representing a SCM revolution for capturing and diffusing customer trends and preferences deep into SC member companies. Also in this respect, we see the applicability of the VSM. 


\section{References}

Anderson, P. (1999) 'Complexity theory and organization science', Organization Science, Vol. 10, pp.216-232.

Barczak, G. (1994) 'Gaining superior performance of new products in the telecommunications industry’, Journal of Business and Industrial Marketing, Vol. 9, pp.19-32.

Barut, M., Faisst, W. and Kanet, J. (2002) 'Measuring supply chain coupling: an information system perspective', European Journal of Purchasing and Supply Management, Vol. 8, pp.161-171.

Bechtel, C. and Jayaram, J. (1997) 'Supply chain management: a strategic perspective', Int. J. Logistics Management, Vol. 8, pp.15-34.

Beer, S. (1979) The Heart of Enterprise. New York, NY: John Wiley and Sons Ltd.

Beer, S. (1985) Diagnosing the System for Organisations. Chichester, UK: John Wiley and Sons.

Beer, S. (1989) 'The viable system model: its provenance, development, methodology and pathology', in R. Espejo and R. Harnden (Eds), The Viable Systems Model. Interpretations and Applications of Stafford Beer's VSM (pp.11-37). Chichester, UK: John Wiley and Sons.

Birou, L. and Fawcett, S. (1994) 'Supplier involvement in integrated product development: a comparison of U.S. and European practices', Int. J. Physical Distribution and Logistics Management, Vol. 24, pp.4-13.

Brocklesby, J. and Cummings, S. (1996) 'Designing a viable organisation structure', Long Range Planning, Vol. 29, pp.49-57.

Campbell, A.J. and Cooper, R.G. (1999) 'Do customer partnerships improve new product success rates?', Industrial Marketing Management, Vol. 28, pp.507-519.

Checkland, P. (1981) Systems Thinking, Systems Practice. Chichester, UK: John Wiley and Sons.

Checkland, P. and Poulter, J. (2006) Learning for Action. A Short Definitive Account of Soft Systems Methodology and its use for Practitioners, Teachers and Students. Chichester, UK: John Wiley and Sons.

Checkland, P. and Scholes, J. (1990) Soft Systems Methodology in Action. Chichester, UK: John Wiley and Sons.

Das, A., Narasimhan, R. and Talluri, S. (2006) 'Supplier integration: finding an optimal configuration', Journal of Operations Management, Vol. 24, pp.563-582.

Espejo, R. and Gill, A. (2007) The Viable System Model as a Framework for Understanding Organizations 2002 [accessed July 23, 2007]. Available at: http://www.phrontis.com/vsm.htm.

Galbraith, J.R. and Kazanjian, R.K. (1986) Strategy Implementation. Structure, Systems and Process. St. Paul, MN: West Publishing Company.

Griffin, A. and Hauser, J.R. (1996) 'Integrating R\&D and marketing: a review and analysis of the literature', Journal of Product Innovation Management, Vol. 13, pp.191-215.

Hertz, S. (2006) 'Supply chain myopia and overlapping supply chains', Journal of Business and Industrial marketing, Vol. 21, pp.208-217.

Jackson, M. (1988) 'An appreciation of Stafford Beer's 'viable system' viewpoint on managerial practice', Journal of Management Studies, Vol. 25, pp.557-573.

Jackson, M. (1992) Systems Methodology for the Management Sciences. New York, NY: Plenum Press.

Lager, T. (2002) 'Product and process development intensity in process industry: a conceptual and empirical analysis of the allocation of company resources for the development of process technology', Int. J. Innovation Management, Vol. 6, pp.105-130.

Lambert, D., Cooper, M. and Pagh, J. (1998) 'Supply chain management: implementation issues and research opportunities', Int. J. Logistics Management, Vol. 9, pp.1-18. 
Lundbäck, M. (2004) Managing the R\&D Integration Process After an Acquisition: Ford Motor Company's Acquisition of Volvo Cars. Department of Business Administration and Social Science, Division of Industrial Organization, Luleå University of Technology, Sweden, Doctoral thesis 2004:25.

Magrath, A.J. and Hardy, K.G. (1994) 'Building customer partnerships', Business Horizons, Vol. 37, pp.24-27.

Mintzberg, H. and van der Heyden, L. (1999) 'Organigraphs: drawing how companies really work', Harvard Business Review, Vol. 77, pp.87-94.

Mirijamdotter, A. (1998) A Multi-Modal Systems Extension to Soft Systems Methodology. Department of Business Administration and Social Science, Luleå University of Technology, Sweden, Doctoral Thesis 1998:06.

Moenaert, R.K., Souder, W.E., De Meyer, A. and Deschoolmeester, D. (1994) 'R\&D-marketing integration mechanisms, communication flows, and innovation success', Journal of Product Innovation Management, Vol. 11, pp.31-45.

Mumford, E. (2000) 'The socio-technical approach to system design', Requirements Engineering, Vol. 5, pp.125-133.

Neale, R.M. and Corindale, D.R. (1998) 'Co-developing products: involving customers earlier and more deeply’, Long Range Planning, Vol. 31, pp.418-425.

Nyström, C.A. (2006a) 'Demands on intranets - viable system model as a foundation for intranet design', AIP Conference Proceedings, Vol. 839, pp.381-387.

Nyström, C.A. (2006b) 'Design rules for intranets according to the viable system model', Systemic Practice and Action Research, Vol. 19, pp.523-535.

Ormerod, R. (1995) 'Putting soft OR methods to work: information systems strategy development at Sainsbury's', The Journal of the Operational Research Society, Vol. 46, pp.277-293.

Ozer, M. (2004) 'Managing the selection process for new product ideas', Research Technology Management, Vol. 47, pp.10-11.

Petersen, K., Handfield, R. and Ragatz, G. (2005) 'Supplier integration into NPD: coordinating product, process and supply chain design', Journal of Operations Management, Vol. 23, pp.371-388.

Prahalad, C. and Ramaswamy, V. (2000) 'Co-opting customer competence', Harvard Business Review, Vol. 78, pp.79-87.

Röder, A. and Tibken, B. (2006) 'A methodology for modelling inter-company supply chains and for evaluating a method of integrated product and process documentation', European Journal of Operational Research, Vol. 169, pp.1010-1029.

Shaw, D.R., Snowdon, B., Holland, A.P., Kawalek, P. and Warboys, B. (2004) 'The viable systems model applied to a smart network: the case of the UK electricity market', Journal of Information Technology, Vol. 19, pp.270-280.

Sobrero, M. and Roberts, E.B. (2002) 'Strategic management of supplier-manufacturer relations in new product development', Research Policy, Vol. 31, pp.159-182.

Song, X.M., Montoya-Weiss, M.M. and Schmidt, J.B. (1997) 'Antecedents and consequences of cross-functional cooperation: a comparison of R\&D, manufacturing, and marketing perspectives', Journal of Product Innovation Management, Vol. 4, pp.35-47.

Strezo, R. (1999) 'The marriage of R\&D and marketing in new product development', Chemical Market Reporter, Vol. 256, p.FR4.

Sutton, D.C. (1995) 'Viable System Model (VSM)', The Journal of the Operational Research Society, Vol. 46, pp.1038-1039.

Swink, M. and Song, M. (2007) 'Effects of marketing-manufacturing integration on new product development time and competitive advantage', Journal of Operation Management, Vol. 25, pp.203-217.

Swink, M. and Mabert, V. (2000) 'Product development partnerships: balancing the need of OEMs and suppliers’, Business Horizons, Vol. 43, pp.59-68. 
Takeishi, A. (2001) 'Bridging inter- and intra-firm boundaries: management of supplier involvement in automobile product development', Strategic Management Journal, Vol. 22, pp.403-433.

Tatikonda, M.V. and Stock, G.N. (2003) 'Product technology transfer in the upstream supply chain', The Journal of Product Innovation Management, Vol. 20, pp.444-467.

Taylor, D. (2005) 'Value chain analysis: an approach to supply chain improvement in agri-food chains', Int. J. Physical Distribution and Logistics Management, Vol. 35, pp.744-761.

Tottie, M. and Lager, T. (1995) 'QFD - linking the customer to the product development process as a part of the TQM concept', $R \& D$ Management, Vol. 25, pp.257-268.

Towner, S. (1994) 'Four ways to accelerate new product development', Long Range Planning, Vol. 27, pp.57-65.

Vachon, S. and Klassen, R. (2006) 'Extending green practices across the supply chain: the impact of upstream and downstream integration', Int. J. Operations and Production Management, Vol. 26, pp.795-821.

von Hippel, E. (1986) 'Lead users: a source of novel product concepts', Management Science, Vol. 32, pp.791-805.

von Corswant, F. and Tunälv, C. (2002) 'Coordinating customers and proactive suppliers: a case study of supplier collaboration in product development', Journal of Engineering and Technology Management, Vol. 19, p.249.

\section{Notes}

${ }^{1}$ http://www.lkab.com/28-02-07.

${ }^{2}$ http://www.ssabox.com/28-02-07.

${ }^{3} \mathrm{http}: / /$ www.ssabtunnplat.com/28-02-07.

${ }^{4}$ http://www.hardtech.ssab.se/28-02-07. 